\title{
Erratum: A feminist genealogy of posthuman aesthetics in the visual arts
}

\author{
Francesca Ferrando
}

Correction to: Palgrave Communications (2016) 2, Article number: 16011. doi: 10.1057/palcomms.2016.11; Published 10 May 2016; Updated 19 May 2016

The statement "This article is published as part of a collection dedicated to multi- and interdisciplinary perspectives on gender studies." was incorrectly inserted at the end of the Introduction. It is now placed at the end of the Abstract.

The sentence "Let us start with Wangechi Mutu (b. 1972), a Kenyan-born artist whose collages melt together the aesthetics of traditional African crafts see Figs. 8 and 9 with science fiction imaginary, bionic prosthetics and Surrealism see Figs. 8 and 9 ...” incorrectly cited Figure 8 and Figure 9 twice; this has now been corrected to read "Let us start with Wangechi Mutu (b. 1972), a Kenyan-born artist whose collages melt together the aesthetics of traditional African crafts with science fiction imaginary, bionic prosthetics and Surrealism (see Figs. 8 and 9)".

The legend for Figure 3 featured an incorrect spelling; "coverd" should have read "covered".

The legend for Figure 7 omitted a space between the characters "@” and "N".

The legend for Figure 8 omitted a space between the characters “@” and “W”.

The legend for Figure 9 omitted a space between the characters “@” and "W”.

The legend for Figure 10 omitted a space between the characters “@” and "L”.

The Acknowledgments was updated to remove mention of the in-house editorial staff in line with the journal guidelines.

The article has been corrected online. 